\title{
Essential role of p21/waf1 in the mediation of the anti-proliferative effects of GHRH antagonist JMR-132
}

\author{
Aspasia-Athina Volakaki, Daniel Lafkas, Eva Kassi, Andrew V Schally ${ }^{1,2}$, \\ Athanasios G Papavassiliou and Hippokratis Kiaris \\ Department of Biological Chemistry, University of Athens Medical School, 75 M. Asias Street, 11527 Athens, Greece \\ ${ }^{1}$ Research Service (151), VA Medical Center, Miami, Florida 33125, USA \\ ${ }^{2}$ Division of Hematology/Oncology, Departments of Pathology and Medicine, University of Miami Miller School of Medicine, Miami, Florida 33101 , USA \\ (Correspondence should be addressed to H Kiaris; Email: hkiaris@med.uoa.gr)
}

\begin{abstract}
$\mathrm{GHRH}$, besides its neuroendocrine action in controlling the release of $\mathrm{GH}$ from the pituitary, stimulates the growth of various cancers in vivo and in vitro by direct mechanism(s). However, the molecular mechanism that mediates these proliferative effects of GHRH in extrapituitary tissues remains poorly characterized. In the present study, we investigated whether the tumor suppressor p21/waf1 is involved in the mediation of the proliferative effects of GHRH in A549 human lung cancer epithelial cells. Exposure of A549 cells to the GHRH antagonist JMR-132 caused a significant inhibition in the rate of cell proliferation. In A549 cells, GHRH suppressed while JMR-132 increased the levels of $p 21$ expression in a dose-dependent manner. This suggests that GHRH could regulate p21 levels. We then evaluated whether p21 is required in $\mathrm{A} 549$ cells for the regulation of cell proliferation by $\mathrm{GHRH}$. To this end, we knocked-down p21 expression in A549 cells by siRNA and assessed the effects of antagonist JMR-132 on cell proliferation. We found that the loss of $p 21$ expression abolished the anti-proliferative effects of JMR-132. Suppression of $p 21$ expression by siRNA in human HT29 colon cancer cells and non-transformed mouse osteoblasts KS483 also blocked the anti-proliferative effects of JMR-132 suggesting that the regulation of cell proliferation by GHRH is $p 21$ dependent. These results shed light on the molecular mechanism of action of $\mathrm{GHRH}$ antagonists in tumor tissues and suggest that the antineoplastic activity of $\mathrm{GHRH}$ antagonists could be considered for the treatment of cancers expressing $p 21$.
\end{abstract}

Journal of Molecular Endocrinology (2008) 41, 389-392

\section{Introduction}

The hypothalamic neuropeptide growth hormonereleasing hormone $(\mathrm{GHRH})$ stimulates the production and release of GH in the pituitary (Kiaris et al. 2005). Besides the hypothalamus, GHRH is produced by various extrapituitary tissues as well as by cancers in which it operates as a stimulator of cell proliferation. Consequently, inhibition of action of GHRH by specific antagonistic peptide analogs may emerge as a novel anticancer strategy (Schally et al. 2001, Kiaris et al. 2003a,b, 2005, Schally et al. 2008). However, despite a well-documented expression of GHRH in various primary and experimental human cancers and cell lines, as well as the clearly demonstrated antineoplastic activity of GHRH antagonists in vitro and in vivo, the knowledge about the mechanism of GHRH action at the subcellular level is limited. The major receptor that mediates the effects of GHRH in the extrapituitary tissues is SV1, a splice variant of the pituitary GHRH receptor that also has ligand-independent activity (Rekasi et al. 2000, Kiaris et al. 2002, Barabutis et al. 2007). With regard to the effects of GHRH on proliferation, at the level of the signaling cascades activated upon binding of GHRH to its receptor(s), a role for mitogen-activated protein kinase (MAPK), and recently Pit-1 transcription factor has been recognized in pituitary cells (Pombo et al. 2000, Solloso et al. 2008). In breast cancer cells, Ras, Raf, and MAPK have been shown to play an essential role in the mediation of the proliferative effects of GHRH (Siriwardana et al. 2006). It has also been shown that in MCF-7 breast cancer cells, upon binding of GHRH to SV1 receptor, the increase in cell proliferation is accompanied by elevated expression of cyclin D1, an important cell-cycle regulator (Barabutis et al. 2007).

In the present study, we investigated the role of p21 in mediating the effects of GHRH in the proliferation of A549 human lung cancer epithelial cells, HT29 human colon cancer cells, and mouse non-transformed osteoblasts KS483. $p 21$ is a cycle-dependent kinase inhibitor that plays a major role in the regulation of cell cycle and has been recognized as a direct target of $p 53$ tumor suppressor gene (el-Deiry et al. 1993, Weiss 2003). While $p 21$ is rarely mutated in primary human cancers, it is frequently characterized by aberrant expression.

DOI: 10.1677/JME-08-0106 Online version via http://www.endocrinology-journals.org 


\section{Materials and methods}

\section{Peptides}

Human GHRH (hGHRH) (1-29)- $\mathrm{NH}_{2}$ was obtained from Dr Parlow (National Hormone and Pituitary Program, National Institute of Diabetes and Digestive and Kidney Diseases, Bethesda, MD, USA). The synthesis of the GHRH antagonist JMR-132 $\left[\mathrm{PhAc}^{0}, \mathrm{D}-\mathrm{Arg}^{2}, \mathrm{Phe}(4-1)^{6}, \mathrm{Ala}^{8}\right.$, $\left.\mathrm{Har}^{9}, \operatorname{Tyr}(\mathrm{Me})^{10}{ }^{10} \mathrm{His}^{11}{ }^{11}, \mathrm{Abu}^{15}, \mathrm{His}^{20}{ }^{2}, \mathrm{Nle}^{27}, \mathrm{D}-\mathrm{Arg}^{28}, \mathrm{Har}^{29}{ }^{2}\right]$ hGHRH(1-29)- $\mathrm{NH}_{2}$, where Abu is $\alpha$-aminobutyric acid, $\mathrm{Har}$ is homoarginine, Nle is norleucine, $\mathrm{PhAc}$ is phenylacetyl, and $\operatorname{Tyr}(\mathrm{Me})$ is $O$-methyltyrosine was reported previously (Buchholz et al. 2007).

\section{Cell culture}

A549 human lung alveolar and HT29 human colon cancer cells were obtained from American Type Culture Collection (Manssas, VA, USA) and maintained in DMEM containing $10 \%$ fetal bovine serum (FBS) and antibiotics/antimycotics. KS483 cells (provided by Dr Karperien, The Netherlands) were grown in a-MEM Phenol Red free medium supplemented with $10 \%$ FBS DCC treated. Tissue culture reagents were obtained from Invitrogen. The rate of cell proliferation was assessed after exposure of cells for $48 \mathrm{~h}$ to GHRH or JMR-132 at concentrations indicated and the cells being counted under inverted microscope after standard trypan blue exclusion assay. Experiments have been performed in triplicates and average values are shown.

\section{siRNA and western blot analysis}

Suppression of $p 21$ in A549 and HT29 cells, or KS483 cells, was achieved by transfecting cells with siRNA specific for human or mouse p21 (Ambion, Austin, TX, USA) respectively according to the manufacturer's instruction using Lipofectamine 2000 reagent. Forty eight hours post-transfection cells were lysed by using RIPA reagent and total protein was subjected to western blot analysis. Antibodies for p21 and actin were obtained from Sigma. All experiments have been performed at least three times independently and similar results were obtained.

\section{Statistical analysis}

Statistical analysis was performed with the Student's $t$-test and results were considered significant when $P<0 \cdot 05$.

\section{Results and discussion}

Initially, we evaluated the effects of GHRH and JMR-132 on the proliferation of A549 cells. As depicted in Fig. 1, the exposure of A549 cells to JMR-132 at $10^{-6} \mathrm{M}$ for

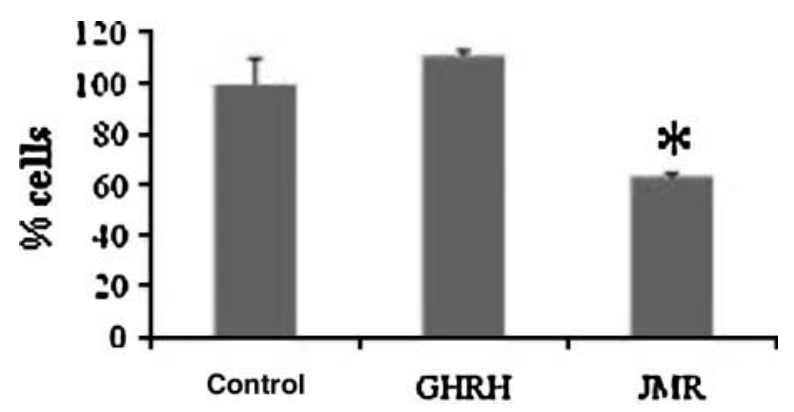

Figure 1 Proliferation of A549 cells in the presence of $\mathrm{GHRH}$ or JMR-132 at $10^{-6} \mathrm{M}$ concentration. All experiments were performed in triplicates and average values are shown. JMR 132 inhibited the proliferation of A549 cells by about 35\% $(P<0.05)$.

$48 \mathrm{~h}$ resulted in $35 \%(P<0 \cdot 05)$ decrease, while GHRH caused about $10 \%$, yet insignificant, stimulation on the rate of cell proliferation suggesting that these cells are sensitive to JMR-132 treatment. Consistent with previous findings on the effects of GHRH antagonists on cell proliferation, no evidence of cytotoxicity was noted in the cells exposed to JMR-132.

Subsequently, we evaluated the effects of these peptides on the expression of the tumor suppressor gene p21/waf1. A549 cells were exposed to GHRH or JMR132 at $10^{-10} \mathrm{M}, 10^{-8} \mathrm{M}$ and $10^{-6} \mathrm{M}$ and the expression of $p 21$ was assessed by western blot analysis. As shown in Fig. 2, increasing concentrations of GHRH caused a dosedependent reduction while JMR-132 produced an elevation in the expression of $p 21$. This is consistent with the effects of these peptides on the proliferation of A549 cells. It is noted, however, that whereas GHRH caused a considerable reduction in p21 levels, its effects on cell proliferation were relatively small when compared with those of JMR-132, implying that p21 levels might not be the limiting factor for the increase in cell proliferation elicited by GHRH. Furthermore, JMR-132 stimulated $p 21$ expression at $10^{-10}$ to $10^{-6} \mathrm{M}$ while it inhibited cell proliferation only at $10^{-6} \mathrm{M}$. Probably this is due to the fact that $p 21$ induction is necessary but not sufficient for cell proliferation inhibition, or that a certain threshold in p21 expression levels should be achieved in order to cause inhibition of cell proliferation.

To determine whether these findings are causatively associated with the anti-proliferative effects of JMR-132 or reflect the reduced proliferation of A549 cells, we knocked down $p 21$ expression by siRNA and then evaluated if JMR-132 was capable of suppressing A549 proliferation. As shown in Fig. 3, in the absence of p21, JMR-132 at $10^{-6} \mathrm{M}$ lost its ability to inhibit A549 cell proliferation, indicating that this cell-cycle regulator is required for the suppression of cell proliferation by antagonistic analogs of GHRH. For this experiment, we used siRNA for p21 at $5 \mathrm{nM}$, because at higher concentrations siRNA for p21 exerted toxic effects (Fig. 3a and unpublished observations). 
(a) GHRH (M)

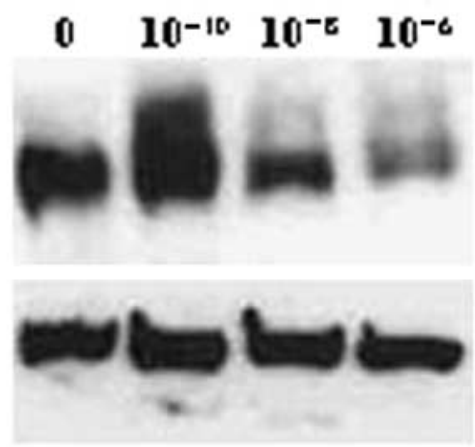

(b)

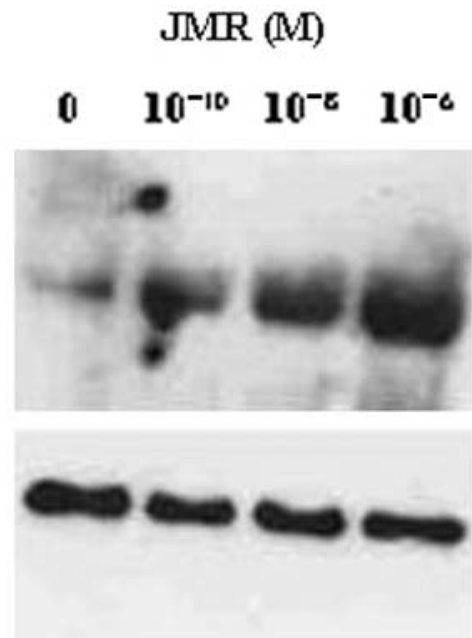

p21

Actin

Figure 2 Modulation of $p 21$ expression by GHRH and JMR-132 in A549 cells. Western blot analysis shows that GHRH causes dosedependent suppression (upper panel), whereas JMR-132 causes dose-dependent induction in the levels of p21 (lower panel).

In order to test whether our findings represent a more general mechanism of GHRH action or they are limited to A549 lung cancer cells we evaluated the consequences of p21 knock-down in cells of diverse origin, such as human colon cancer cells and mouse non-transformed osteoblasts KS483. In HT29 cells, we found that JMR-132 stimulated $p 21$ expression at $10^{-6} \mathrm{M}-10^{-10} \mathrm{M}$, notwithstanding the fact that stimulation was slightly more potent at $10^{-8} \mathrm{M}$ (Fig. 4). Subsequently, we knocked-down p21 by siRNA and tested the effects on cell proliferation, of JMR-132 at $10^{-8} \mathrm{M}$ alone or in combination with p21 siRNA at $10 \mathrm{nM}$. As shown in Fig. 4, suppression of $p 21$ expression significantly inhibited the anti-proliferative effects of JMR-132 $(P<0 \cdot 01)$. Similar results were obtained with KS483 with the exception that in these cells, while treatment with JMR-132 $10^{-6} \mathrm{M}$ had no considerable effect on $p 21$ expression (not shown), it effectively blocked the suppression of p21 caused by estradiol at $10^{-7}$ M. Furthermore, siRNA for p21 at $5 \mathrm{nM}$ (a)

\section{siRNA (nM)}
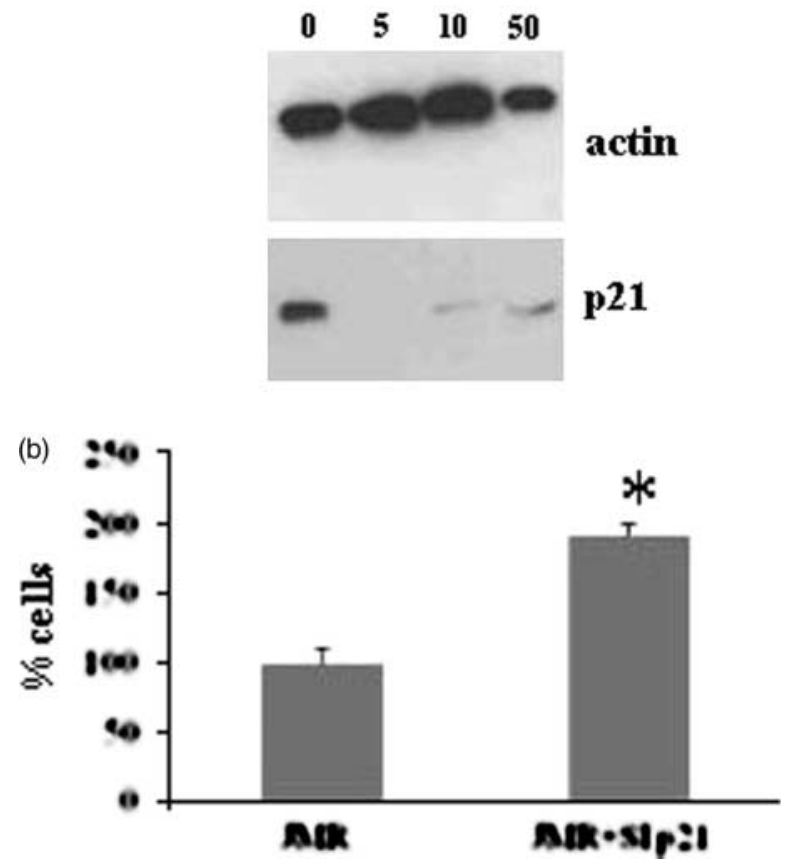

Figure 3 Requirement of p21 for the anti-proliferative effects of JMR-132 in A549 cells. (a) Transfection of siRNA for p21 reduced considerably p21 levels as revealed by western blot analysis. The p21 suppression was more efficient at $5 \mathrm{nM}$ siRNA, while at higher concentrations siRNA treatment was toxic. (b) In the presence of $5 \mathrm{nM}$ of siRNA for p21, JMR-132 was incapable of suppressing the proliferation of A549 cells $(P<0 \cdot 005)$.

significantly inhibited the anti-proliferative effects of JMR-132 in the presence of $10^{-7} \mathrm{M}$ estradiol (Fig. 5). Therefore, we conclude that modulation of $p 21$ expression by GHRH antagonists likely represents a general mechanism for the action of these agents in cell growth.

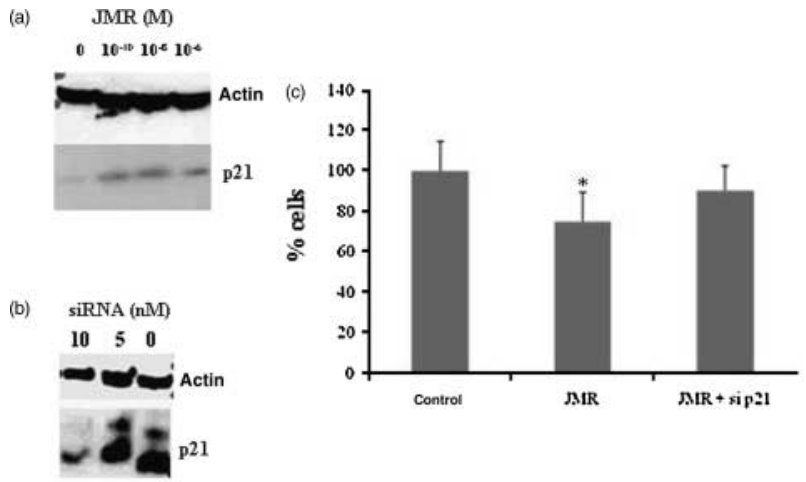

Figure 4 Effects of JMR-132 in p21 expression and proliferation of HT-29 human colon cancer cells. (a) Effective stimulation of $p 21$ expression by JMR-132 at $10^{-6} \mathrm{M}-10^{-10} \mathrm{M}$. (b) siRNA for p21 at $10 \mathrm{nM}$ potently inhibited $p 21$ expression. (c) JMR-132 at $10^{-8} \mathrm{M}$ inhibited HT-29 cell proliferation and this effect was abolished in cells transfected by siRNA for $\mathrm{p} 21$ at $10 \mathrm{nM}$. ${ }^{*} P<0.01$ versus controls. 
(a)

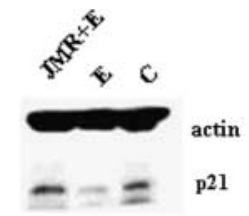

(b)

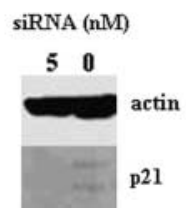

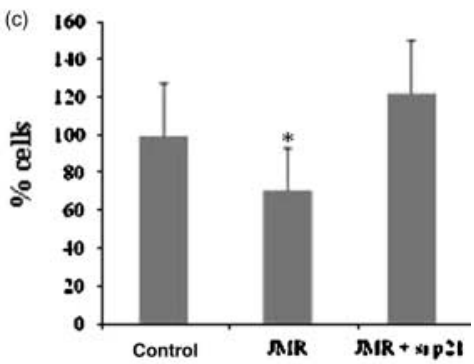

Figure 5 Effects of JMR-132 in p21 expression and proliferation of KS483 mouse non-transformed osteoblasts. (a) While treatment with JMR-132 $10^{-6} \mathrm{M}$ alone had no considerable effects in p21 expression (not shown), effectively blocked the suppression of p21 caused by estradiol at $10^{-7}$ M. (b) siRNA for p21 at $5 \mathrm{nM}$ potently inhibited p21 expression. (c) In the presence of $10^{-7} \mathrm{M}$ estradiol, JMR-132 at $10^{-6} \mathrm{M}$ inhibited KS483 cell proliferation and this effect was abolished in cells transfected by siRNA for p21 at $5 \mathrm{nM}$. ${ }^{*} P<0.01$ versus controls.

In none of the cells used above, siRNA for p21 alone did not affect cell proliferation considerably, and scrambled siRNA also did not affect $p 21$ expression (data not shown).

Thus, considering previous findings on the mechanism of action of GHRH analogs in extrapituitary tissues, the interaction of GHRH with its membrane receptors, may initiate a signaling cascade that involves Ras, Raf, and MAPK and which eventually results in the modulation of $p 21$ expression in the nucleus. This mechanism of modulation of $p 21$ expression appears to play a major role in the mediation of the effects of GHRH analogs on cell proliferation.

These results shed light on the mechanism of action of GHRH antagonists by linking directly GHRH to the cell-cycle machinery, indicating that p21 is a critical target of GHRH analogs. Our results also imply that the GHRH antagonists should be considered particularly for the therapy of cancers that express p21 activity.

\section{Declaration of interest}

The authors declare that there is no conflict of interest that could be perceived as prejudicing the impartiality of the research reported.

\section{Funding}

This work was supported by the grant 05 NONEU-13 from GSRT, and Kapodistrias 06, ELKE, University of Athens, Greece.

\section{Acknowledgements}

We thank Dr Karperien (Leiden University, The Netherlands) for the KS483 cells.

\section{References}

Barabutis N, Tsellou E, Schally AV, Kouloheri S, Kalofoutis A \& Kiaris H 2007 Stimulation of proliferation of MCF-7 breast cancer cells by a transfected splice variant of growth hormone-releasing hormone receptor. PNAS 104 5575-5579.

Buchholz S, Schally AV, Engel JB, Hohla F, Heinrich E, Koester F, Varga JL \& Halmos G 2007 Potentiation of mammary cancer inhibition by combination of antagonists of growth hormone-releasing hormone with docetaxel. PNAS 104 1943-1946.

el-Deiry WS, Tokino T, Velculescu VE, Levy DB, Parsons R, Trent JM, Lin D, Mercer WE, Kinzler KW \& Vogelstein B 1993 WAF1, a potential mediator of p53 tumor suppression. Cell 75 817-825.

Kiaris H, Schally AV, Busto R, Halmos G, Artavanis-Tsakonas S \& Varga JL 2002 Expression of splice variant for GHRH receptor SV1 mediates mitogenic effects in 3T3 fibroblasts. PNAS 99 196-200.

Kiaris H, Chatzistamou I, Schally AV, Halmos G, Varga JL, Koutselini H \& Kalofoutis A 2003a Ligand-dependent and -independent effects of GHRH receptor splice variant 1. PNAS 100 9512-9517.

Kiaris H, Koutsilieris M, Kalofoutis A \& Schally AV $2003 b$ Growth hormone - releasing hormone (GHRH) and extra-pituitary tumorigenesis: therapeutic and diagnostic applications of GHRH antagonists (review). Expert Opinion on Investigational Drugs 12 $1385-1394$.

Kiaris H, Schally AV \& Kalofoutis A 2005 Extra-pituitary effects of growth hormone - releasing hormone. Vitamins and Hormones $\mathbf{7 0}$ $1-24$.

Pombo CM, Zalvide J, Gaylinn BD \& Diéguez C 2000 Growth hormonereleasing hormone stimulates mitogen-activated protein kinase. Endocrinology 141 2113-2119.

Rekasi Z, Czompoly T, Schally AV \& Halmos G 2000 Isolation and sequencing of cDNAs for splice variants of growth hormonereleasing hormone receptors from human cancers. PNAS $\mathbf{9 7}$ 10561-10566.

Schally AV, Comaru-Schally AM, Nagy A, Kovacs M, Szepeshazi K, Plonowski A, Varga JL \& Halmos G 2001 Hypothalamic hormones and cancer. Frontiers in Neuroendocrinology 22 248-291.

Schally AV, Varga JL \& Engel JB 2008 Antagonists of growth-hormonereleasing hormone: an emerging new therapy for cancer. Nature Clinical Practice. Endocrinology $\mathcal{E} \mathcal{O}$ Metabolism 4 33-43.

Siriwardana G, Bradford A, Coy D \& Zeitler P 2006 Autocrine/paracrine regulation of breast cancer cell proliferation by growth hormone releasing hormone via Ras, Raf, and mitogen-activated protein kinase. Molecular Endocrinology 20 2010-2019.

Solloso A, Barreiro L, Seoane R, Nogueira E, Cañibano C, Alvarez CV, Zalvide J, Diéguez C \& Pombo CM 2008 GHRH proliferative action on somatotrophs is cell-type specific and dependent on Pit-1/GHF-1 expression. Journal of Cellular Physiology 215 140-150.

Weiss RH 2003 p21Wafl/Cip1 as a therapeutic target in breast and other cancers. Cancer Cell 4 425-429.

Received in final form 1 August 2008

Accepted 2 September 2008

Made available online as an Accepted Preprint 2 September 2008 